\title{
Avaliação de Política de Concorrência: Estimação de Danos no Cartel de Postos de Gasolina em Londrina
}

\author{
Simone Maciel Cuiabano*
}

\begin{abstract}
Resumo: Este trabalho busca estimar os danos causados pelo cartel nos postos de gasolina na região sul do Brasil usando tanto uma equação reduzida quanto um modelo estrutural de demanda e oferta. Documentos do Conselho Administrativo de Defesa Econômica (CADE) ajudam a caracterizar os postos envolvidos na colusão nos mercados de etanol e gasolina. O objetivo é avaliar os efeitos da política de concorrência comparando o montante do dano estimado com as multas aplicadas. Em adicional, esse trabalho também contribui para a literatura sobre substituição entre gasolina e etanol, uma vez que os dados apontam que o etanol é percebido como substituto perfeito e é preço inelástico. Os resultados mostram que o sobre preço gerado pelo cartel foi de ordem de $4.6 \%$ a $6.6 \%$ no mercado de gasolina e de até $12 \%$ no mercado de etanol. As multas aplicadas, contudo, devem considerar a probabilidade de o cartel ser descoberto e, dada sua baixa probabilidade, as multas aplicadas no presente caso parecem estar alinhadas com esse objetivo.
\end{abstract}

Palavras-chave: cartel; estimação reduzida; avaliação de política

JEL: L41; L71; D43

Abstract: I estimate the fuel retailer cartel damages in the south of Brazil using reduced and structural forms for supply and demand. Brazilian Competition Authority (CADE) documents help to characterize the ethanol and gasoline retailers involved in the collusion. The objective is to evaluate competition policy by comparing the amount of estimated damages with the amount of applied fines. This paper also adds an important result to gasoline substitution, as data shows ethanol is perceived as a perfect substitute and it is price inelastic. Results show an overcharge of $4.6 \%$ to $6.6 \%$ in the gasoline market and up to $12 \%$ in the ethanol market during collusion. Fines should consider the deterrence effect and, giving the low probability of detection, CADE's applied fines seemed to be in line with this objective.

Key words: cartel; reduced form estimation; policy evaluation

JEL codes: L41; L71; D43

Departamento de Estudos Econômicos, Conselho Administrativo de Defesa Econômica (DEE/Cade). (simone.cuiabano@cade.gov.br/scuiabana@gmail.com).

Agradecimentos à Superintendência de Defesa da Concorrência da Agência Nacional de Petróleo pela disponibilidade dos dados e à equipe do DEE/Cade pelo suporte. Este trabalho foi realizado durante o programa de Pós-doutorado na Toulouse School of Economics, 


\section{Introdução}

A avaliação de política tem sido uma das prioridades entre Autoridades de Concorrência ao redor do mundo. Em 2016, a Organização de Cooperação e Desenvolvimento Econômico (OCDE) lançou um guia de referência para avaliação expost das decisões tomadas por órgãos antitrustes, pois demonstram o custo-benefício desse tipo de política pública. Nesse artigo, busca-se estimar os danos causados pelo cartel entre postos de combustíveis na cidade de Londrina, Paraná, de forma a promover uma avaliação da política de concorrência no Brasil por meio da comparação entre a vantagem auferida e o montante das multas impostas pelo Conselho Administrativo de Defesa Econômica (CADE). Como em outras jurisdições, cartéis são ilegais no país, estando os participantes sujeitos a investigações administrativas e criminais ${ }^{1}$. A Lei 12.529/11 determina que as multas não podem ser inferiores à vantagem auferida com o crime; no entanto, o CADE raramente recorre a esta disposição ao estabelecê-las. Dessa forma, o presente artigo busca contribuir para avaliar se as multas impostas têm tido relação com o dispositivo legal ${ }^{2}$.

Violações antitruste no varejo de combusível não são comuns ao redor do mundo, apesar de suscitar preocupações entre os membros da OCDE (2013). Embora haja uma compreensão de que a volatilidade dos preços dos combustíveis pode ser a resultante de outros fatores - como choques de demanda ou de custos, estratégias de preços (Clark e Houde, 2013, 2014) - a falta de compreensão do público em geral pode suscitar dúvidas sobre a eficiência dos órgãos de concorrência. Na experiência brasileira, a quantidade de reclamações no setor varejista de combustíveis toma quase 1/4 da carga de trabalho do CADE. De 2005 a 2010, a instituição recebeu 200 reclamações por ano relacionadas a este setor. No entanto, a autoridade condenou apenas 15 sindicatos e varejistas de combustíveis em diferentes municípios até 2015 por falta de prova direta. Dessa forma, busca-se analisar um caso que representa um dos maiores esforços empreendidos para a manutenção do cenário concorrencial.

\footnotetext{
1 O artigo 36 da Lei 12,529/11 esclarece os parâmetros para a investigação de cartéis no Brasil. Investigações criminais são responsabilidade do Ministério Público e sob jurisdição do Superior Tribunal de Justiça.

2 A Lei 12.529/11 estabelece que as multas podem ir de 0,1\% a 20\% do faturamento bruto da empresa ou do grupo ao qual pertence a empresa no setor econômico afetado pela conduta no ano anterior ao início das investigações. Essa regra tem sido usada com frequência pelo Tribunal do CADE devido às dificuldades técnicas no cálculo da vantagem auferida.
} 
Este trabalho está dividido em 7 partes, incluindo esta introdução: na sessão 2 é feita uma breve revisão da literatura sobre avaliação de política de concorrência e estimação de danos. Na sessão 3 são explicadas as principais características do cartel em Londrina, usando informações fornecidas nos autos do processo. A sessão 4 detalha a metodologia a ser adotada e apresenta algumas estatísticas descritivas disponíveis para o caso. A sessão 5 apresenta os principais resultados da estimativa de elasticidades-preço e os resultados do modelo de simulação de preços nos mercados de etanol e gasolina. A Sessão 6 compara os resultados dos danos estimados com as multas aplicadas. A sessão 7 conclui o artigo, destacando alguns resultados que podem ser úteis para futuras discussões sobre estimativa de dano e avaliação da política de concorrência.

\section{Revisão da Literatura}

A avaliação de política de concorrência em matéria de penas aplicadas a carteis passa por dificuldades semelhantes às encontradas na literatura sobre estimativa de danos, pois é necessário considerar que as penalidades deveriam considerar não apenas o impacto à sociedade, mas seu efeito dissuasório, de forma a evitar que novos atos ilícitos venham a ocorrer.

A literatura internacional sobre estimativa de danos começou a ser ampliada desde que as ações privadas de reparação começaram a ser implementadas tanto nos EUA como na Europa. Clark et al (2004) foram os primeiros a compilar um estudo de quantificação de danos ao cartel para a Comunidade Europeia, fazendo uma revisão estruturada das decisões judiciais. Connor (2009) examinou o litígio antitruste do cartel de lisina de forma bastante intensa e enfatizou os problemas existente na quantificação de danos, uma vez que o método antes e depois (before and after) é bastante crítico nos casos em que a formação de cartéis ocorreu após uma recessão e, em tais circunstâncias, o cálculo pode ser subestimado e os danos exagerados. Dijk e Verboven (2007) também separam os métodos de quantificação de danos que utilizam indicadores comparativos dos métodos baseados em informações diretas sobre o mercado cartelizados. Os autores se utilizam da análise da perda crítica: o sobrepreço é determinado encontrando um ponto de equilíbrio em que a demanda diminui, dado um aumento de preço particular, e o comparando com a perda esperada.

A discussão sobre o efeito dissuasório das multas dos cartéis é também uma área de pesquisa bastante difundida e que tem relação direta com o presente trabalho. 
Vários estudos chegaram à conclusão de que as multas de cartéis foram, na verdade, subótimas, considerando a vantagem auferida e a probabilidade de detecção do crime. Por isso, autores como Connor (2009) e Hüschelrath e Weigand (2010) defendem que as autoridades da concorrência devem investir não apenas em melhores instrumentos de detecção de cartéis, mas também em penas maiores.

Buscando fazer uma avaliação ex-post, Laitenberger e Smuda (2013) publicaram um estudo para estimar os danos sofridos por consumidores alemães no cartel de detergentes, ativo entre 2002 e 2005 em oito países europeus. Os autores fizeram um exercício usando a metodologia antes e depois (before and after) com uma base de dados em painel de consumidores para cada categoria de detergente e obtiveram um sobrepreço de 6,72\%. Os autores observaram que categorias de detergentes não relacionadas ao cartel mantiveram-se competitivas no período e, com base nessa informação, repetiram o exercício usando a técnica de diferenças em diferenças (difference-in-differences) e obsrevaram um sobrepreço semelhante à técnica anterior, de 6,93\%.

No Brasil, Lucinda e Seixas (2016) publicaram um estudo sobre o cálculo de danos no cartel de peróxidos. Usando três metodologias diferentes (séries temporais, diferença de diferenças e modelo estrutural) foi possível concluir que os danos e as multas foram muito similares em termos de valor. No entanto, considerando a importância do efeito de dissuasão, haveria duas opções: ou o montante das multas deveria ser reclamado em ações de reparação de danos pelos agentes privados; ou as multas deveriam ser mais altas. No caso da primeira opção, apesar de ainda pouco executada pelo sistema judical brasileiro, ele poderia ser considerada um instrumento de política pública. Recentemente, Afonso, e Féres (2017) refizeram uma estimativa de dano proposta pela Conselheira Cristiane Alkmim no cartel de gás liquefeito de petróleo (GLP). Utilizando o modelo de regressão multivariada, os autores estimaram um sobrepreço entre 10\% e 13\%, resultando em danos na ordem de um bilhão de reais. Já com o modelo de diferenças em diferenças, alterando o grupo de controle usado pela Conselheira, os autores obtiveram um sobrepreço de 15,97\%, alcançando danos na ordem de R \$1,2 bilhão.

\section{O Cartel dos Postos de Gasolina em Londrina}

\section{A. Investigação e Condenação}


Em 12 de agosto de $2007^{3}$, a Secretaria de Direito Econômico (SDE) ${ }^{4}$ abriu uma investigação de cartel após receber um ofício do Departamento de Polícia do Paraná sobre o processo criminal envolvendo donos de postos de gasolina na região metropolitana de Londrina (Londrina, Cambé, Jataizinho e Ibiporã). As interceptações telefônicas do distribuidor de combustíveis Oil Petro revelaram a existência de cartel no varejo de combustíveis nessas localidades. Em 29 de agosto de 2007, foi deflagrada a operação “Medusa III”, com a cooperação da SDE, da Secretaria de Acompanhamento Econômico (SEAE) e da polícia local, cumprindo mandados de busca e apreensão em 16 postos de combustíveis nos municípios citados ${ }^{5}$.

As interceptações telefônicas e a documentação obtida mostraram que a colusão teve início quando um dos postos, localizado numa rodovia em Cambé ("Posto Paizão" ou Etiel Comercio de Combustiveis Ltda.), a cerca de 15 quilometros de distância do centro de Londrina, reduziu o preço do etanol no início de 2007. Em resposta, um de seus concorrentes (“Rede Posto Carajas” ou Auto Posto Gasosan Ltda.), a cerca de 12,5 quilômetros de Londrina, também reduziu o preço de venda do etanol, alcançando o preço de R\$0,94 por litro. Essa “guerra de preços” atraiu motoristas acostumados a abastecer no centro de Londrina, cuja média de preços variava entre $\mathrm{R} \$ 1,39$ e $\mathrm{R} \$ 1,74$ por litro de etanol e entre R\$2,39 e R\$2,55 por litro de gasolina. A Figura 1 ilustra a distribuição geográfica dos postos investigados. A Tabela 1 mostra a distância linear e o tempo percorrido entre o centro de Londrina e os postos participantes do cartel.

\footnotetext{
3 O CADE condenou 15 cartéis envolvendo postos de combustíveis até 2015. A maioria deles está relacionada ao período de liberalização de preços (1999-2004) para o qual não há dados disponíveis (CADE (2014)).

4 O Sistema Brasileiro de Defesa da Concorrência (SBDC), até 2011, era composto por 3 órgãos: a Secretaria de Acompanhamento Econômico (SEAE) do Ministério da Fazenda, responsável pela instrução processual de fusões e aquisições; a Secretaria de Defesa Econômica (SDE), ligada ao Ministério da Justiça, responsável pela instrução processual de denúncias de infração à ordem econômica; e o CADE, tribunal administrativo responsável pela decisão final sobre os atos de concentração e julgamentos sobre infrações.

${ }^{5}$ Processo público 08012.0116681/2007-30.
} 


\section{Figura 1}

\section{Localização dos postos condenados}

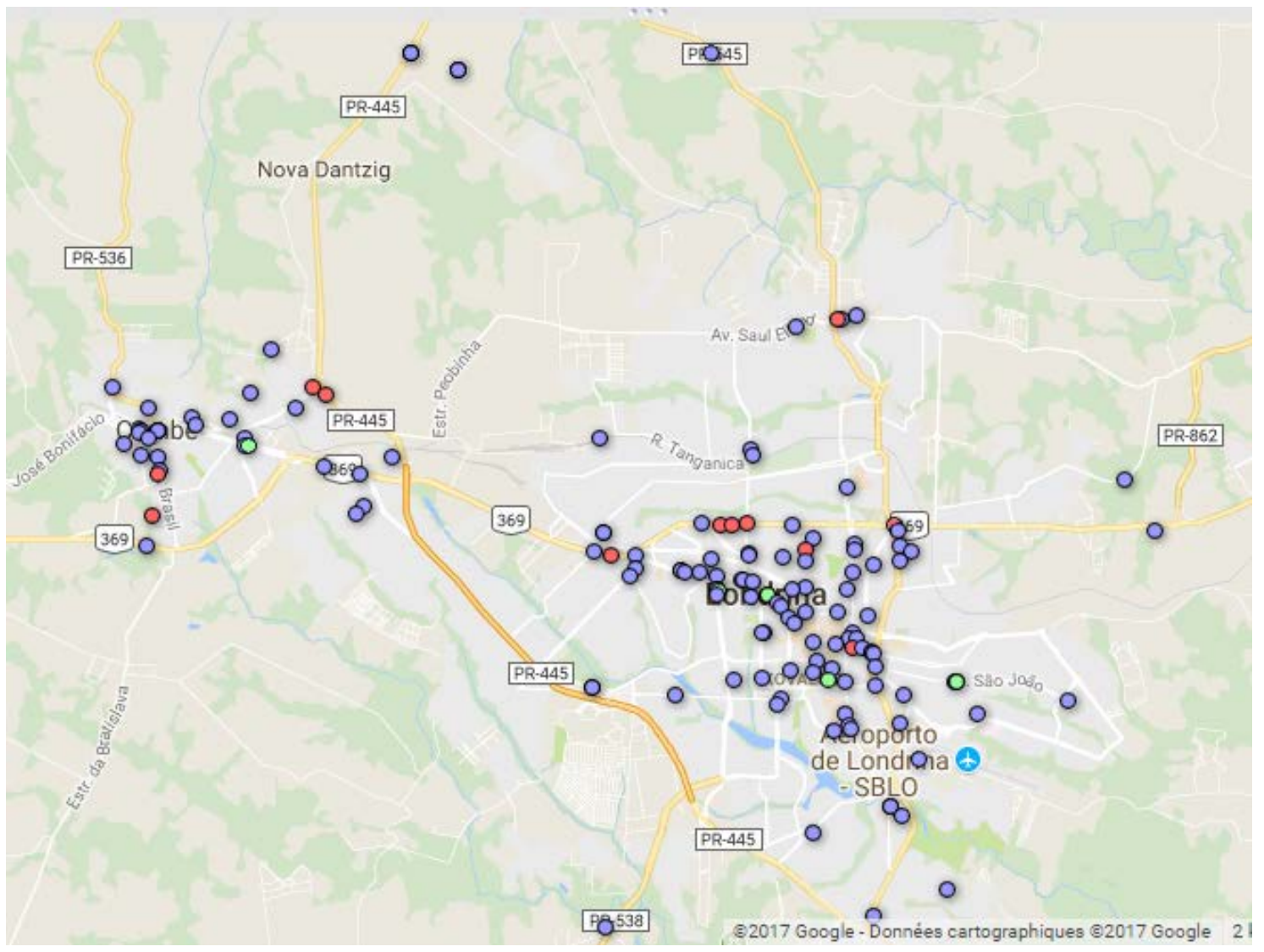

Elaboração própria. Obs: Pontos vermelhos e verdes representam os postos condenados pelo CADE. Pontos verdes indicam postos pertencentes a grupos com algum grau de parentesco, que iniciaram as conversas sobre a "guerra de preços". 
TABELA 1. LISTA DE POSTOS ENVOLVIDOS NO CARTEL E SUAS DISTÂNCIAS

\begin{tabular}{|c|c|c|c|}
\hline Posto & $\begin{array}{l}\text { Distância linear } \\
(\mathrm{km})\end{array}$ & $\begin{array}{l}\text { Distância dirigida } \\
(\mathrm{km})\end{array}$ & $\begin{array}{l}\text { Tempo } \\
\text { percorrido } \\
\text { (minutos) }\end{array}$ \\
\hline Auto Posto 10 de Dezembro Ltda, & 1,5 & 2,7 & 7 \\
\hline Kalahan Comercio de Combustiveis Ltda, & 3,4 & 7,1 & 12 \\
\hline Auto Posto Exposição Ltda, & 4,6 & 5,1 & 10 \\
\hline Etiel Comércio de Combustíveis Ltda, (Posto Paizão) & 13,9 & 14,9 & 23 \\
\hline A, A, Fevereiro, Doino e Machado Ltda, & 2,1 & 3,4 & 8 \\
\hline Auto Posto Paiaguás_Ltda, & 2,6 & 3,8 & 7 \\
\hline AVN Comercio de combustiveis Ltda-Me, & 13,9 & 15,4 & 24 \\
\hline C,O, Bolognesi \& Bolognesi Ltda, (Posto Tropical) & 1,0 & 2,1 & 5 \\
\hline J Ramalho \& Cia Ltda, (Auto Posto Versailles III) & 10,9 & 11,6 & 19 \\
\hline Posto Novo Oriente Ltda, & 0,5 & 1,3 & 5 \\
\hline Auto Posto Portelão Ltda, & 10,6 & 11,6 & 19 \\
\hline
\end{tabular}

Entre abril e maio de 2007, donos de postos de combustíveis localizados no centro de Londrina iniciaram conversas com os proprietários dos postos em Cambé para encerrarem a chamada “guerra de preços”, dando início a uma série de ações coordenadas, como datas para realizarem o reajustes de preços bem como o alinhamento de preços entre eles $^{6}$. Os líderes do cartel intervinham da administraçao dos postos, forçando ${ }^{7}$ todos os associados a combinarem seus preços. De acordo com a documentação disponível no processo, a política de uniformização dos preços não exigia um grande esforço por parte dos organizadores do cartel porque os postos condenados eram considerados líderes de preços em suas localidades, servindo de preço de referência para postos vizinhos.

\footnotetext{
6 The pressure involved physical threatening, verbal abuse and harassment of retailers.

${ }^{7}$ The agreement went up to the 2 nd decimal level price combination in which some retailers could raise or drop their prices up to $\mathrm{R} \$ 0,03$, adjusting it to demand changes.
} 
O cartel operou até o final de agosto de 2007, quando foram executados mandados de busca e apreensão e ordems de prisão temporária. Até então, o cartel decidia os preços “justos” entre os postos localizados em Cambé e em Londrina: no primeiro município, o litro do etanol era de R \$1,18 e, o litro da gasolina, de R\$2,32; no segundo, o etanol custava $\mathrm{R} \$ 1,33$ e, a gasolina, $\mathrm{R} \$ 2,43$.

Essas diferenças de preços entre etanol e gasolina entre os municípios são importantes para explicar como postos de gasolina, aparentemente não pertencentes ao mesmo mercado relevante, de repente se tornaram competidores vorazes e objeto de retalização de postos distantes. O etanol é considerado um substituto perfeito quando seu preço por litro atinge $70 \%$ do preço da gasolina. Contudo, mesmo que gasolina e etanol sejam precificados de forma similar em termos em custo por quilômetro rodado, Salvo e Huse (2013) ainda reiteram que há preferências dos consumidores em termos de gostos, restrições orçamentárias (a população de renda mais alta prefere gasolina ao etanol), idade, preocupação com o meio ambiente, que podem afetar essa substitutibilidade.

Todavia, no caso do cartel acima, suponha um consumidor que precise escolher entre gasolina e etanol. Considerando apenas a preferência de preços, se ele enfrenta um piso inferior de R $\$ 2,39$ por litro de gasolina, ele observa que abastecer com etanol é mais rentável se seu preço por litro for inferior à $\mathrm{R} \$ 1,68$. Porém, é necessário considerar se esse preço está sendo oferecido pelo mesmo posto ou por algum vizinho, senão ele ainda precisa considerar os custos de deslocamento. Se ele usa um veículo que faz $10 \mathrm{~km}$ por litro de gasolina e $7 \mathrm{~km}$ por litro de álcool, o litro do etanol vendido em até $70 \%$ do oferecido no posto central justificaria uma viagem de ida e volta de $30 \mathrm{~km}$ para encher o tanque com 40 litros de etanol - o que resultaria em uma economia de $50 \%$ se o cliente resolvesse abastecer com gasolina no centro de Londrina. Na documentação disponibilizada no processo, donos de postos no centro ressaltam que as vendas chegaram a cair entre 300 e 500 litros $^{8}$ por dia durante a competição de preços.

O cartel operava em dois grupos: o central, coordenado pela família Guarda e outros dois proprietários de postos, eram responsáveis pela determinação da política de preços e seu monitoramento. Essa ação também envolveu a participação de um distribuidor de combustível, a Oil Petro, cujo diretor comercial, Mauro Guarda, mantinha relações verticais com um varejista de mesmo nome. O segundo grupo envolveu os principais postos de combustíveis em Londrina e Cambé, considerados líderes de preço

8 Não há informação se as perdas foram apenas de etanol ou gasolina. 
na região pela sua capacidade de influenciar o mercado. A documentação do CADE mostra que esses postos concordaram com as políticas propostas pelo grupo ao alterar seus preços nas datas sugeridas, influenciando o resto dos postos vizinhos.

Além da condenação penal, o CADE aplicou multas que somaram mais de R\$10 milhões, de acordo com a Tabela 2. A definição das multas foi feita com base nos arts.37 e 45 da Lei 12.529/11: de acordo com a Conselheira-Relatora, sua decisão foi de adotar uma alíquota entre $13 \%$ e $15 \%$ do faturamento anual bruto das empresas, dependendo da participação direta e/ou indireta dos acusados. Embora a Lei também defina explicitamente que as multas não podem ser inferiores à vantagem auferida, esse último dispositivo é pouco utilizado devida à sua complexidade de estimação, de forma que a definição de alíquotas sobre o faturamento é a regra mais utilizada.

TABELA 2. Lista DOS POSTOS E ADMINISTRADORES CONDENADOS

\begin{tabular}{lc}
\hline \hline & Multas (R\$) \\
1. AVN Comércio de Combustíveis Ltda. (Auto Posto Bonanza) & 610314.46 \\
2. Mazzarelo \& Cia Ltda. (Auto Posto Flamboyant) & 851280.00 \\
3. Oíl Petro Brasileira de Petróleo Ltda. & 851280.00 \\
4. DGJR Comércio de Combustíveis Ltda. (Posto Versailles e Posto Versailles II) & 851280.00 \\
S. J Ramalho \& Cia Ltda. (Auto Posto Versailles III) & 851280.00 \\
6. Auto Posto 10 de Dezembro Ltda. & 851280.00 \\
7. Posto_ Novo_Oriente Ltda. & 851280.00 \\
8. C.O. Bolognesi \& Bolognesi Ltda. (Posto Tropical) & 851280.00 \\
9. Auto Posto Paiaguás_Ltda. & 487134.86 \\
10. Etiel Comércio de Combustíveis Ltda. (Posto Paizão) & 744870.00 \\
11. Auto Posto Brasília de Londrina Ltda (Posto Meninão) & 744870.00 \\
12. Auto Posto Exposição Ltda. & 744870.00 \\
1. Mauro Cesar Guarda & 255384.00 \\
2. Jonatas Cerqueira Guarda & 127692.00 \\
3. Claudir_Osmir Bolognesi & 255384.00 \\
4. Itauby Netto José Ramalho & 255384.00 \\
5. Djalma Eugênio Guarda & 346931.17 \\
6. Djalma Eugênio Guarda Júnior & 79340.88 \\
7. Sergio Goes_de_Oliveira & 290499.30 \\
8. Edson Fernandes Gimenes & 63327.53 \\
\hline TOTAL & 962.20 \\
\hline Fonte. Processo administrativo 08012.011588/2007-30
\end{tabular}

\section{Estimação econométrica}

A.Metodologia 
Para estimar a vantagem auferida pelos cartelistas e os danos, são utilizadas as informações do CADE sobre a duração do cartel, a qual seja, de maio à agosto de 2007. A quantificação dos danos envolve um exercício de simular qual teria sido o preço cobrado na ausência do cartel durante o período citado. Para tanto, é necessário caracterizar as condições da demanda nos mercados de etanol e gasolina em Londrina.

Parte-se de um modelo de concorrência oligopolista que considera a existência de discriminação de preço devido ao tipo de combustível e às características dos postos. De acordo com a documentação referente ao cartel, os varejistas precificam seus combustíveis de forma diferenciada de cada um, conforme a localização e o fluxo da demanda na região. Essas características são observadas mesmo durante o cartel, quando os participantes do conluio definiam as diferenças de preço em até a terceira casa decimal.

Dado que um posto comercializa etanol e gasolina, o lucro individual de cada um é dado pela seguinte equação:

$$
\pi^{j}=\left(p_{g}-w_{g}-c_{g}\right) s_{g}+\left(p_{e}-w_{e}-c_{e}\right) s_{e}
$$

Onde $p_{g}, p_{e}$ são os preços de gasoline e etanol, respectivamente, $w_{g}, w_{e}$ são os custos de distribuição de cada um dos combustíveis, $c_{g}, c_{e}$ são os custos marginais de constantes atribuídos à cada combustível. A parcela de mercado (market shares) de gasolina e etanol são dadas por $s_{g}, s_{e}$. Consideram-se deslocadores de custo o preço de distribuição, a distância em relação ao centro de Londrina, o número de bombas e a tancagem de cada combustível, características individuais de cada posto.

Assumindo a existência de um equilibro Bertrand-Nash de estratégias puras, o preço de cada um dos combustíveis deve satisfazer as seguintes condições de primeira ordem:

$$
\begin{aligned}
& s_{g}+\left(p_{g}-w_{g}-c_{g}\right) \frac{\partial s_{g}}{\partial p_{g}}=0 \\
& s_{e}+\left(p_{e}-w_{e}-c_{e}\right) \frac{\partial s_{e}}{\partial p_{e}}=0
\end{aligned}
$$

As equações (2) e (3) implicam na condição que o vetor $\gamma$ das margens de cada posto equivale ao preço de venda $p$ menos o preço do custo de distribuição $w$ e menos o custo de distribuição $c$ :

$$
\gamma=p-w-c
$$

Estimações de margens de preço e custo requerem informações sobre o formato da demanda de modo a ser possível inferior as margens de cada posto. Anderson (2012) desenvolve um modelo de demanda por etanol como substituto da gasolina no qual o 
consumidor escolhe aquele combustível com o menor preço equivalente ao etanol. A demanda agregada, tanto para gasolina quanto para o etanol, tem uma forma suave na qual depende dos preços relativos quando estes são distribuídos de forma contínua. Desse modo, as equações log-lineares da demanda agregada para cada um dos combustíveis são como se seguem:

$$
\begin{aligned}
& \ln _{g i t}=\propto_{g}+\beta_{0} \operatorname{lncars}_{t}-\beta_{1} \ln p_{g i t}+\beta_{2} \ln p_{e i t}-\beta^{d} \text { lntimetravel }_{\text {in }}+\varepsilon_{i j} \\
& {\ln Q_{e i t}}=\propto_{e}+\beta_{3} \text { lncars }_{t}-\beta_{4} \ln _{\text {eit }}+\beta_{2} \ln _{\text {git }}-\beta^{d} \text { lntimetravel }_{i n}+\varepsilon_{i j}
\end{aligned}
$$

Onde $Q_{g i t}, Q_{e i t}$ são as quantidades de gasolina e etanol vendidas por cada posto $i$ no mês $t ; p_{g j} p_{e j}$ são, respectivamente, os preços de varejo da gasolina e do etanol, ; timetravel $^{9}$ captura o tempo de viagem entre o posto $i$ e o posto $n$, considerado o posto líder no centro de Londrina; $\varepsilon$ é um índice dos atributos não observáveis de cada posto. As equações incluem as informações sobre localização dos postos, de forma a ser testada se o tempo de deslocamento do centro até os postos afetam as preferências da demanda, como apontado por Houde (2012).

As equações reduzidas da demanda serão utilizadas para a estimação dos preços da gasolina e do etanol em forma de um painel para cada posto $i$ no tempo $t$ tal qual as equações (7) e (8):

$$
\begin{aligned}
& p_{\text {git }}=\propto_{0}+\beta_{1} p_{\text {eit }}+\beta_{2} \text { timetravel }_{j n}+\beta_{3} w_{g}+\beta_{4} c_{g}+\epsilon_{i j} \\
& p_{e j t}=\propto_{5}+\beta_{6} p_{\text {git }}+\beta_{7} \text { timetravel }_{j n}+\beta_{8} w_{e}+\beta_{9} c_{e}+\epsilon_{i j}
\end{aligned}
$$

Onde $w$ são os custos relacionados aos preços dos distribuidores e a outros deslocadores de custos, como as informações sobre tancagem e se o posto é bandeira branca ou não. Uma vez estimados os parâmetros para cada combustível, incluir-se-á uma dummy para os postos envolvidos no cartel durante o período indicado (maio à agosto de 2007), de forma que será utilizado um estimador linear com efeitos aleatórios de tal forma que:

$$
\begin{aligned}
& p_{\text {git }}=\propto_{0}+\beta_{1} p_{\text {eit }}+\beta_{2} \text { timetravel }_{j n}+\beta_{3} w_{g}+\beta_{4} c_{g}+\varphi_{\text {eta }} d_{\text {cartellDg }}+\epsilon_{i j} \\
& p_{\text {ejt }}=\propto_{5}+\beta_{6} p_{\text {git }}+\beta_{7} \text { timetravel }_{j n}+\beta_{8} w_{e}+\beta_{9} c_{e}+\varphi_{\text {gas }} d_{\text {cartellDe }}+\epsilon_{i j}
\end{aligned}
$$

Para o modelo estrutural, são estimadas as equações (5) e (6) usando as informações dos preços dos distribuidores, tancagem e preço médio dos postos vizinhos em um raio de $1 \mathrm{~km}$ como instrumentos. Essas variáveis permitem controlar para mudanças nos preços que não são relacionadas às quantidades vendidas. Uma vez

\footnotetext{
9 Data collect on May 13, 2017 from 8:30 pm to 14pm, local time of Londrina.
} 
estimadas as elasticidades, é possível simular o preço hipotético (“but for price”) de cada posto considerando suas próprias regras de mark-up e os custos de aquisição de cada combustível.

\section{B. Base de Dados e Estatísticas}

Foram utilizadas informações do próprio processo administrativo para caracterizar os cartelistas e o período no qual o cartel operou. Ademais, foram agregadas outras 3 bases de dados contendo informações relativas aos postos de combustíveis em Londrina e Cambé ${ }^{10}$, obtidas junto à Agência Nacional do Petróleo, Gás Natural e Biocombustíveis - ANP): (i) um painel não balanceado dos postos de combustíveis, contendo preços de aquisição e de vendas semanais de gasolina, etanol e diesel entre 2007 e 2009, contendo informações sobre a bandeira do posto e localização georeferenciada; (ii) um painel mensal da quantidade comercializada de gasolina, etanol e diesel por posto de combustível entre 2007 e 2009; (iii) características dos postos, como número de bombas e tancagem, em forma de cross-section. Como essa última informação se trata de dados de 2014, foi necessário checar as informações no próprio site da ANP para analisar os postos que não estavam em operação entre 2007 e 2009 e incluir aqueles sem informação para 2014. Informações sobre tempo de viagem e distâncias a serem percorridas por veículos privados foram obtidas via Google API para cada posto, considerando o centro da cidade como referência de percurso ${ }^{11}$. A amostra inclui preços e quantidades para 154 postos localizados em ambos municípios para um período de 36 meses (3 anos), totalizando 5.544 observações. Contudo, devido à inexistência de dados de preços para todos os postos em algumas semanas, um painel completo se forma para apenas 440 observações de etanol e 443 de gasolina.

Para deflacionar os dados, utilizou-se o Índice de Preços ao Consumidor Amplo (IPCA) no Estado do Paraná, fornecido pelo Instituto Brasileiro de Geografia e Estatística (IBGE). Alguns deslocadores de custos também foram adicionados, como o preço internacional do açúcar e do petróleo, divulgados pelo Fundo Monetário Internacional (FMI). O número de veículos licenciados mensalmente em Londrina e Cambém, fornecidos pelo Departamento de Trânsito do Paraná (Detran/PR), também foram utilizados.

\footnotetext{
10 A coleta de preços da ANP não abrange os municípios de Ibiporã ou Jataizinho devido à metodologia amostral. Informações sobre preço e quantidade para cada varejista não estão disponíveis nos apartados restritos, mas foram cedidas gentilmente pela ANP.

11 O Posto Transamérica, cnpj 07.775.477/0001-98, foi usado como referência no centro de Londrina.
} 
As Tabelas 3 e 4 resumem as estatísticas para as principais variáveis da base de dados. Na média, os postos de combustíveis venderam 75.000 litros de gasolina, 50.000 litros de etanol e 76.000 litros de diesel nos dois municípios por mês. Observa-se, todavia, que esses valores se alteraram ao longo dos anos, com destaque para o aumento de $20 \%$ nas vendas de etanol e de 18\% de diesel em 2009, na comparação com 2007.

TABELA 3. EsTATÍSTICAS DE VOLUMES

\begin{tabular}{|c|c|c|c|c|c|c|c|c|c|c|c|c|}
\hline & & m geral & & & 2007 & & & 2008 & & & 2009 & \\
\hline $\begin{array}{l}\text { Quantidade } \\
\text { (lt/mês) }\end{array}$ & Média & $\mathrm{DP}$ & \# & Média & DP & $\#$ & Média & DP & $\#$ & Média & DP & $\#$ \\
\hline Gasolina & 74,914 & 54,056 & 157 & 76,680 & 51,187 & 127 & 74,914 & 54,056 & 157 & 68,599 & 53,176 & 130 \\
\hline Etanol & 49,790 & 45,410 & 160 & 33,246 & 29,923 & 132 & 49,790 & 45,410 & 160 & 56,655 & 50,565 & 131 \\
\hline Diesel & 76,271 & 13,3078 & 154 & 71,456 & 15,108 & 118 & 76,271 & 13,307 & 154 & 89,905 & 12,996 & 130 \\
\hline
\end{tabular}

O resumo das estatísticas de quantidades aponta para a existência de heterogeneidade entre os postos de combustíveis em Londrina no período analisado. $\mathrm{O}$ maior desvio padrão (DP) diz respeito à venda de gasolina, na comparação com as vendas de diesel, por exemplo. A comercialização de etanol tornou-se mais dispersa ao longo dos anos - o desvio padrão passou de 30 mil litros em 2007 para 50 mil litros em 2009.

Essa heterogeneidade também é captada pelas características dos postos, como número de bombas e tancagem. No geral, os postos apresentam maior variação no número de bombas de gasolina e menos variação no número de bombas de diesel, embora este último varie mais no tamanho da tancagem. Os postos condenados no cartel, contudo, apresentaram características mais similares em relação ao número de bombas de gasolina e etanol, corroborando a informação disponível nos autos do processo de investigação de que os postos têm estrutura de custos similares. Em média, os postos participantes do cartel tinham 6 bombas de gasolina e 4 de etanol. Ao contrário dos outros, cartelistas tinham mais bombas de diesel, o que reflete o fato do acordo ter contado com postos localizados na rodovia, com maior demanda por diesel. Os participantes do cartel também estavam geograficamente mais espalhados, como aponta a Tabela 4. 
TABela 4. Estatísticas de PReÇOS E CARACTERÍSTICAS dos Postos

\begin{tabular}{lcccccc}
\hline \hline & \multicolumn{2}{c}{ Geral } & \multicolumn{2}{c}{ Em colusão } & \multicolumn{2}{c}{ Fora da colusão } \\
\hline & Média & DP & Média & DP & Média & DP \\
\hline Gasolina, preço (R\$/Lt) & 2.451 & 0.099 & 2.370 & 0.071 & 2.451 & 0.099 \\
Etanol, preço (R\$/Lt) & 1.466 & 0.206 & 1.192 & 0.122 & 1.468 & 0.205 \\
Diesel, preço (R\$/Lt) & 1.914 & 0.088 & 1.767 & 0.041 & 1.916 & 0.087 \\
Bombas, gasolina & 5.047 & 3.056 & 3.857 & 2.762 & 5.055 & 3.057 \\
Bombas, etanol & 3.506 & 1.938 & 3.000 & 1.342 & 3.509 & 1.941 \\
Bombas, diesel & 2.659 & 2.156 & 3.571 & 2.891 & 2.653 & 2.150 \\
Tancagem, gasolina (lt) & 32.118 & 12.473 & 25.000 & 10.607 & 32.167 & 12.472 \\
Tancagem, etanol (lt) & 22.412 & 10.783 & 19.286 & 6.944 & 22.433 & 10.803 \\
Tancagem, diesel (lt) & 24.529 & 20.463 & 28.571 & 13.887 & 24.501 & 20.500 \\
Distância (Km) & 5.538 & 5.233 & 6.455 & 4.977 & 5.532 & 5.235 \\
Distância dirigida (minutos) & 10.859 & 6.591 & 11.636 & 6.823 & 10.854 & 6.590 \\
\hline Source: own cas & & & & & & \\
\hline
\end{tabular}

Source: own calculations.

O preço por litro médio de gasolina foi de R $\$ 2,45$ (US\$1,22) no período, com uma dispersão de 0,09 centavos. Durante o cartel, os postos participantes tiveram preços médios mais baixos que os postos não participantes (diferença de 0,08 centavos); contudo, os preços dos cartelistas apresentou menor dispersão. Padrões semelhantes foram observados nos preços do etanol e do diesel: apesar de os preços do etanol e do diesel entre os cartelilstas ter sido $\mathrm{R} \$ 0,27$ e $\mathrm{R} \$ 0,15$, respectivamente, menor que os preços dos não cartelistas, a variação de preços entre os postos foi menor. $\mathrm{O}$ fato de os postos participantes do cartel estarem localizados em regiões mais afastadas do centro de Londrina explica a razão dos preços mais baixos, além do fato de que estes postos possuem uma maior tancagem de diesel, parte importante do faturamento total, ao contrário dos postos não participantes do cartel.

Um fato importante sobre a operação no varejo de combustíveis no Brasil diz respeito o modelo de negócios do setor. Até 1997, postos de combustíveis estavam necessariamente vinculados ao distribuidor e carregavam a marca dele, atuando como unidades de franquias. Dessa forma, as transações entre os distribuidores e os postos ocorriam via contratos fixos, com exclusividade de venda do distribuidor à montante. Após a desregulamentação do setor, o novo modelo permitiu que os postos mantivessem contratos de compra com distribuidores diversos, sem exclusividade. Os postos de bandeira branca, portanto, não têm um distribuidor único nem funcionam como modelos de franquias, podendo obter preços mais baixos já que têm poder de negociação com diversos distribuidores. Em Londrina, 36\% dos postos no período estavam classificados 
como bandeira branca. Entre os cartelistas, a maior proporção de postos bandeira branca (58\%) ajuda a caracterizar o menor preço desses em relação aos não cartelistas. Ressaltase aqui o papel da Oil Petro, distribuidora livre, que ajudou a liderar e coordenar o cartel, envolvendo laços de parentescos entre ela e proprietários dos postos condenados.

\section{Resultados}

\section{A. Gasolina}

Dada as informações sobre o período do cartel bem como das firmas participantes, as estimações por meio de equações reduzidas permitem-nos observar como os preços foram afetados. As estimações dos preços da gasolina e do etanol foram feias considerando deslocadores de demanda e oferta como: distância (tempo de viagem do centro de Londrina para cada um dos postos, incluindo os de Cambé), bandeira do posto, tamanho da tancagem e número de bombas. Não foram considerados os custos referentes à comercialização de outros combustíveis porque $90 \%$ deles comercializam tanto gasolina como etanol.

Para gasolina, foram testadas diferentes especificações entre as quais a mais robusta inclui o preço do etanol comercializado pelo próprio posto. Esse fato não é uma novidade para o mercado brasileiro devido à substitubilidade desses combustíveis. Por exemplo, um aumento de $\mathrm{R} \$ 1,00$ no preço do etanol (“PRECOVENDAETANOLd”) provocou um aumento de 0,089 centavos na gasolina ${ }^{12}$.

Tempo de viagem em minutos ("time”) e distância percorrida (“dist”) são correlacionadas; dessa forma, apenas uma dela foi mantida na especificação final. A distância percorrida do centro de Londrina para os postos apresentou sinal negativo, como esperado, embora em baixa magnitude: a cada quilômetro percorrido, a queda de preços foi menor que um centavo de Real. Aqui seria necessária a complementação de informações sobre as rotas de preferência dos consumidores, o que demandaria uma pesquisa de origem e destino, nao disponível nas bases de dados pesquisadas.

O preço de aquisição dos distribuidores ("PRECOCOMPRAGASd”) foi a variável de maior e mais direto impacto sobre os preços do varejo: um aumento de $\mathrm{R} \$ 1,00$ nas distribuidoras acaba por ter maior repasse para os consumidores, de ordem de R\$1,04 a R \$1,05 de aumento na bomba. Por outro lado, o fato de o posto optar por ser bandeira branca (“d_branca”) não teve muito impacto no preço do varejo, o que pode ser um

\footnotetext{
${ }^{12}$ Aproximadamente 50\% dos veículos do Paraná possuiam tecnologia flex-fuel no período analisado. (Ministério do Meio Ambiente (2011). Gráfico 70, página 90).
} 
indício de comportamento de colusão tácita já existente entre os postos de ambas municipalidades. Uma maior capacidade de armazenamento (“tanks_gas”) esteve associada a menores preços, como esperado na literatura; seus efeitos, contudo, foram marcadamente menores que os coeficientes positivos associados a um aumento de preços, refletindo uma capacidade dos administradores de postos a repassar aumentos de custos aos consumidores, ao invés de retê-los.

Durante o cartel, o preço das firmas envolvidas foi $\mathrm{R} \$ 0,13$ centavos maior que em outros períodos, antes ou depois. Contudo, não se pode assumir esse coeficiente como sobrepreço do cartel, uma vez que há efeitos relacionados à elasticidade preço cruzada com o consumo do etanol. 
TABELA 5. REGRESSÕES REDUZIDAS PARA GASOLINA

\begin{tabular}{|c|c|c|c|c|}
\hline Especificação & 1 & 2 & 3 & 4 \\
\hline \multicolumn{5}{|c|}{ Dependente: preço de venda de gasolina } \\
\hline \multicolumn{5}{|l|}{ Fatores de demanda } \\
\hline \multirow{2}{*}{ Constante } & 0.1096105 & 0.1036447 & 0.0931006 & 0.043569 \\
\hline & $(0.043469)$ & $(0.0386335)$ & $(0.0386833)$ & $(0.0151887)$ \\
\hline \multirow{2}{*}{ Dist } & -0.0171896 & -0.017215 & -0.0170129 & -0.002309 \\
\hline & $(0.0063476)$ & $(0.0062115)$ & $(0.0061915)$ & $(0.0008059)$ \\
\hline \multirow{2}{*}{ Time } & 0.00895 & 0.0090318 & & \\
\hline & $(0.0050273)$ & $(0.0049132)$ & & \\
\hline \multicolumn{5}{|l|}{ Fatores de custo } \\
\hline \multirow{2}{*}{ PRECOCOMPRAGASd } & 1.053047 & 1.052917 & 1.049946 & 1.047202 \\
\hline & $(0.0205515)$ & $(0.0205155)$ & $(0.0204499)$ & $(0.0177587)$ \\
\hline \multirow{2}{*}{ d_branca } & -0.0084004 & & & \\
\hline & $(0.0227797)$ & & & \\
\hline \multirow[b]{2}{*}{ PRECOVENDAETANOLd } & 0.0897138 & 0.0896416 & 0.0980785 & 0.0937471 \\
\hline & $(0.0288679)$ & $(0.0287533)$ & $(0.0269798)$ & $(0.0286924)$ \\
\hline \multirow{2}{*}{ tanks_gas } & -0.0023663 & -0.0022545 & -0.0019947 & -0.0014993 \\
\hline & $(0.0009149)$ & $(0.0008318)$ & $(0.0008364)$ & $(0.0008217)$ \\
\hline \multicolumn{5}{|l|}{ Colusão } \\
\hline \multirow{2}{*}{ dummyidcartel } & & & 0.1384666 & 0.1392501 \\
\hline & & & $(0.0629351)$ & $(0.0631914)$ \\
\hline sigma_u & 0.03668116 & 0.03356806 & 0.01212934 & 0.04053157 \\
\hline sigma_e & 0.10310978 & 0.10473205 & 0.04987219 & 0.10356332 \\
\hline Rho & 0.11233969 & 0.09315895 & 0.05584701 & 0.13282551 \\
\hline R-squared (overall) & 0.9989 & 0.999 & 0.999 & 0.9991 \\
\hline
\end{tabular}

Erro padrão em (). Os resultados das especificações 3 e 4 são significantes a 1\%. Elaboração própria.

Para a estimação de demanda estrutural, de forma a obter o efeito cruzado entre gasolina e etanol, estimou-se a equação (5) instrumentalizando-a com informações sobre o custo de aquisição da distribuidora, tancagem e preço médio dos postos vizinhos em um raio de 1 quilometro. Os efeitos dos preços nas quantidades apresentaram os sinais esperados e confirmam a baixa elasticidade-preço da gasolina na região: um aumento de $1 \%$ nos preços provoca uma queda na quantidade demandada inferior a $0,6 \%$. Por sua vez, o efeito de um aumento de preço de $1 \%$ no etanol provoca um aumento no consumo de gasolina também na ordem de $0,6 \%$. 
TABELA 6. ESTIMAÇÃO DE DEMANDA PARA GASOLINA

\begin{tabular}{llll}
\hline \hline $\begin{array}{l}\text { Especificação } \\
\text { Dependente: logaritmo da qtde de gasolina }\end{array}$ & & 2 & 3 \\
_cons & 25.55381 & 26.94924 & 26.84867 \\
& $(6.698227)$ & $(6.828287)$ & $(6.840229)$ \\
lprecovendagas & -0.4547253 & -0.5590767 & -0.5734533 \\
& $(0.3077597)$ & $(0.3060727)$ & $(0.3066743)$ \\
lprecovendaetanol & 0.5183416 & 0.5999931 & 0.6123401 \\
& $(0.2816827)$ & $(0.2788484)$ & $(0.2793655)$ \\
lcars & -1.182731 & -1.291657 & -1.303361 \\
& $(0.5447383)$ & $(0.5551726)$ & $(0.5559122)$ \\
ltime & & & 0.1144555 \\
sigma_u & & & $(0.1375862)$ \\
sigma_e & 0.63035553 & 0.60124663 & 0.6053546 \\
rho & 0.21563805 & 0.18700162 & 0.18835183 \\
\hline
\end{tabular}

Erro padrão em (). 1. Instrumentos: lpm_conc_1km lprecocompragas; 2. lpm_conc_1km lprecocompragas ltanksg; 3. lpm_conc_1km lprecocompragas ltanksg. Elaboração própria.

O sobrepreço é então calculado supondo um preço a ser obtido (but-for-price) como resultado de uma concorrência monopolistica na qual cada posto, apesar de concorrerem entre si, possuem um pequeno poder de mercado e adicionam uma regra de mark-up aos preços de aquisição da distribuidora.

(11) $p_{i t}^{\text {butprice }}=$ costs $_{\text {git }}+\left(-\frac{s}{\varepsilon}\right)$

Onde $s$ é a parcela de mercado associada ao posto e $\varepsilon$ a elasticidade-preço da demanda.

O sobrepreço calculado no modelo estrutural também é positivo e significativo, em média R\$0,38 centavos maior que o preço concorrencial. Em percentual, o sobrepreço no modelo estrutural foi de 9,8\%, enquanto o resultado obtido na equação reduzida aponta para um sobrepreço de 4,7\%. A Figura 1 compara os preços obtidos em ambos modelos com o preço praticado pelos varejistas. 
Figura 1. Preços Realizados de Gasolina e seus Preços estimados de Venda sob COMPETIÇÃO

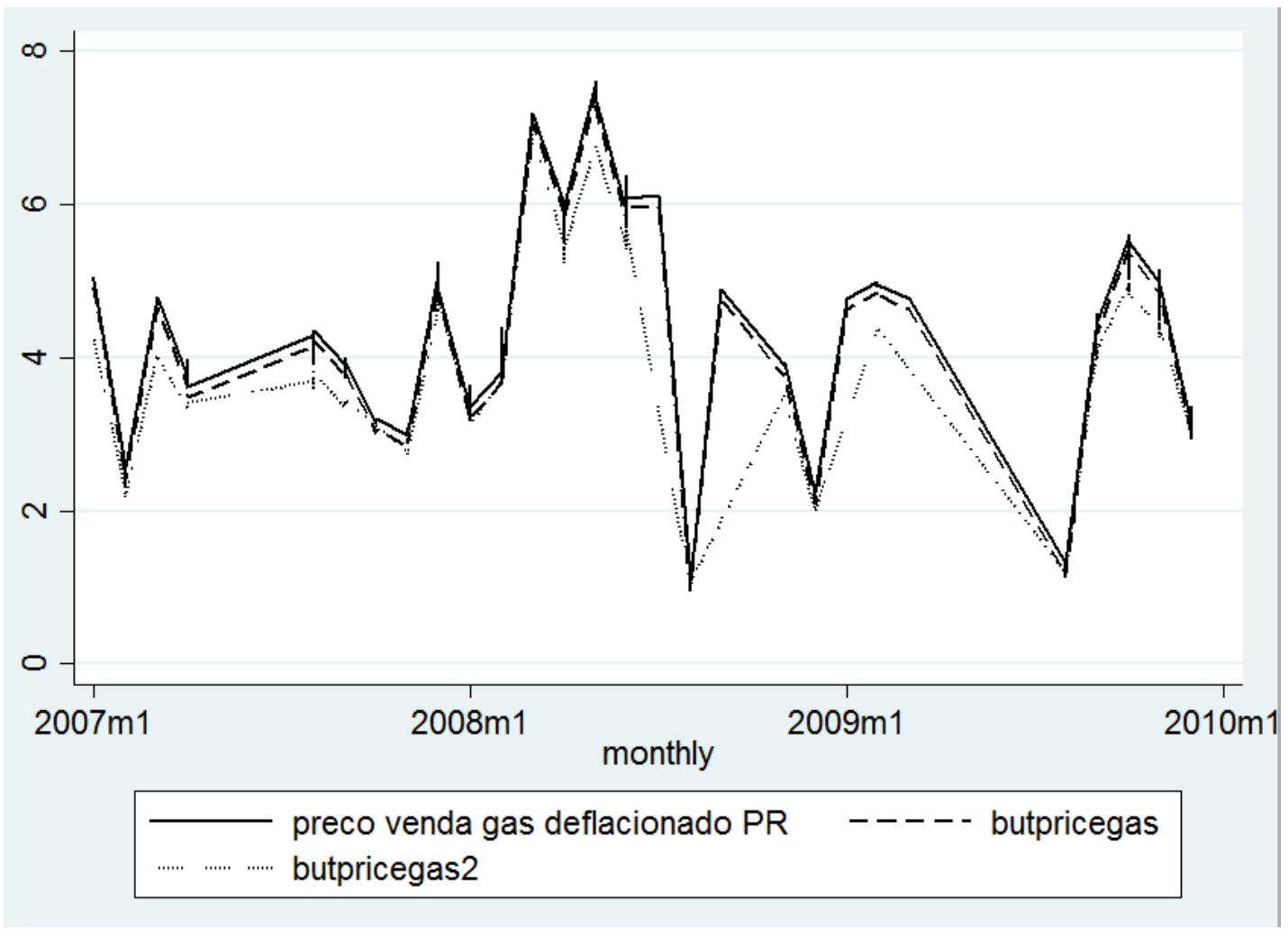

Fonte. Elaboração própria “Butpricegas” resultado do modelo de equação reduzida; “Butpricegas2” resultado do modelo estrutural.

\section{B. Etanol}

Nas especificações para estimação do preço do etanol, foram incluídas as mesmas variáveis de demanda usadas anteriormente (“dist” e "time”). Para deslocadores de custos, foram incluídos o preço de aquisição de etanol do distribuidor ("PRECOCOMPRAETANOLd”), bem como o efeito de substituição da gasolina ("PRECOVENDAGASd"). A principal diferença entre as estimações de gasolina e etanol está na inclusão de um índice de preço internacional do açúcar (“sugar”), uma vez que a cana de açúcar é insumo essencial para ambos. No Brasil, os produtores possuem flexibilidade de trocar a produção de açúcar para etanol e vice-versa devido ao baixo custo. Até 2006, a produção de açúcar e de etanol estava dividida quase em 50\% do total de cana-de-açúcar disponível. A partir de então, o aumento na comercialização de carros flex fuels provocou um aumento na produção de etanol, reduzindo a disponibilidade de açúcar. Contudo, a decisão dos produtores está diretamente relacionada ao preço futuro do açúcar no Mercado externo. A exemplo, a combinação de açúcar/etanol foi 
maximizada em 2011 e 2012 devido à alta do preço da commodity ${ }^{13}$, causando uma menor produção de etanol no país.

O impacto do preço internacional do açúcar foi positivo e significante nas especificações 3 e 4. Embora na especificação 1 o sinal obtido tenha sido negativo, o modelo em questão incluía variáveis extrar que acabaram sendo retiradas devido ao baixo poder explanatório, como tempo e distância percorrida. Assim como nas estimações de demanda de gasolina, a distância percorrida gerou impacto negativo sobre os preços do etanol, mas em pequena magnitude. Também não foi identificada influência da informação sobre a bandeira do posto (“d_branca”), de forma que essa variável foi retirada da última especificação, assim como a informação sobre o número de bombas de etanol ("bicos_eta”).

O preço de aquisição dos distribuidores ("PRECOCOMPRAETANOLd”) apresentou maior efeito direto sobre o preço dos varejistas, assim como no caso da gasolina, embora a transmissão aos consumidores tenha sido menor. Uma hipótese para esse fato pode ser uma maior preferência dos consumidores por gasolina, fazendo com que as firmas absorvam parte do aumento de custo para evitar estoques excessivos. $\mathrm{O}$ efeito do preço da venda da gasolina ("PRECOVENDAGASd”) sobre o preço do etanol, contudo, apresentou um coeficiente maior que o contrário (efeito do aumento de preço do etanol sobre o preço da gasolina). Isso ajuda a mostrar que a estratégia de precificação dos postos considera não apenas custos, mas as preferências dos consumidores e o efeito substituição. Um aumento de preços de gasolina no varejo permite aos postos aumentarem o preço do etanol em maior proporção que o contrário, respeitando a "regra de bolso” de eficiência energética na proporção de 70\% entre etanol e gasolina.

Durante o cartel, os preços do etanol foram 0,038 centavos mais baixos que os preços fora do período do cartel. Esse resultado controverso apenas reflete a estratégia adotada pelos postos em manter um equilíbrio de preços entre gasolina e etanol e modo a estabilizar a renda dos participantes do cartel. É importante lembrar que este teve início após uma "guerra de preços" no mercado de etanol local, fazendo com que o lucro dos postos competidores fosse reduzido devido à maior preferência dos consumidores por etanol que em gasolina. Mantendo uma proporção de equilíbrio entre os preços de etanol e gasolina, mesmo que, em teoria, o primeiro tivesse preço mais baixo, os cartelistas maximizavam as vendas de ambos produtos.

\footnotetext{
13 Covrig (2014).
} 
TABELA 7. REGRESSÕES REDUZIDAS PARA ETANOL

\begin{tabular}{|c|c|c|c|c|}
\hline Especificação & 1 & 2 & 3 & 4 \\
\hline \multicolumn{5}{|c|}{ Dependente: preço de venda de etanol } \\
\hline \multicolumn{5}{|l|}{ Deslocadores de demanda } \\
\hline \multirow{2}{*}{ _cons } & 0.2293977 & -0.6820153 & -0.7618369 & -0.7903439 \\
\hline & $(0.1088252)$ & $(0.1000504)$ & $(0.0948181)$ & $(0.0952531)$ \\
\hline \multirow{2}{*}{ dist } & 0.0030712 & 0.0105773 & & -0.0050015 \\
\hline & $(0.0134118)$ & $(0.0080061)$ & & $(0.0023574)$ \\
\hline \multirow{2}{*}{ time } & -0.0052832 & -0.013321 & -0.0053529 & \\
\hline & $(0.0110065)$ & $(0.006522)$ & $(0.0018683)$ & \\
\hline \multicolumn{5}{|l|}{ Deslocadoes de custo } \\
\hline \multirow{2}{*}{ PRECOCOMPRAETANOLd } & 1.161412 & 0.4200158 & 0.3800242 & 0.3804374 \\
\hline & $(0.0207021)$ & $(0.0603231)$ & $(0.0548631)$ & $(0.0564332)$ \\
\hline \multirow{2}{*}{ d_branca } & 0.1917472 & 0.048704 & & \\
\hline & $(0.0469142)$ & $(0.0323915)$ & & \\
\hline \multirow{2}{*}{ PRECOVENDAGASd } & & 0.4033752 & 0.4252455 & 0.4249725 \\
\hline & & $(0.0317775)$ & $(0.0290005)$ & $(0.0298097)$ \\
\hline \multirow{2}{*}{ tank_eta } & -0.0032696 & -0.0022551 & -0.002262 & -0.0025557 \\
\hline & $(0.0020202)$ & $(0.001217)$ & $(0.0011911)$ & $(0.0012002)$ \\
\hline \multirow{2}{*}{ sugar } & -0.0049045 & 0.0535773 & 0.0575578 & 0.0578314 \\
\hline & 0.0066979 & 0.0064634 & 0.0059689 & 0.0060654 \\
\hline \multicolumn{5}{|l|}{ Colusão } \\
\hline \multirow{2}{*}{ dummyidcartel } & & & & -0.0382886 \\
\hline & & & & $(0.1550836)$ \\
\hline sigma_u & 0.08968003 & 0.00690577 & 0 & 0 \\
\hline sigma_e & 0.18962417 & 0.13691181 & 0.14413066 & 0.14483054 \\
\hline rho & 0.18278497 & 0.00253769 & 0 & 0 \\
\hline R-squared (overall) & 0.9846 & 0.9899 & 0.9932 & 0.9932 \\
\hline
\end{tabular}

Erro padrão em (). Resultados são significantes em 1\%.. Elaboração própria.

A elasticidade-preço encontrada para etanol foi semelhante à encontrada para gasolina, apontando para mais um indício de substituição entre os produtos (-0.57 e 0.55). Em ambas estimações, o tempo ou distância percorridos ("ltime”) apresentou sinal positivo, i.e., quanto maior a distância do posto para o centro da cidade, o motorista opta por maior quantidade de combustível. 
TABELA 8. ESTIMAÇÃO DE DEMANDA PARA ETANOL

\begin{tabular}{llll}
\hline \hline $\begin{array}{l}\text { Especificação } \\
\text { Dependente: logaritmo da qtde de etanol }\end{array}$ & & 2 & 3 \\
_cons & -40.45567 & -43.16309 & -40.73871 \\
& $(13.92972)$ & $(17.50656)$ & $(13.93184)$ \\
lprecovendagas & 0.6206255 & 1.105276 & 0.6165984 \\
& $(0.6998246)$ & $(0.8535769)$ & $(0.7000006)$ \\
lprecovendaetanol & -0.5546346 & -1.022595 & -0.5548431 \\
& $(0.6414875)$ & $(0.7785791)$ & $(0.6415611)$ \\
lcars & 4.206299 & 4.40747 & 4.205395 \\
ltime & $(1.129817)$ & $(1.419404)$ & $(1.129979)$ \\
sigma_u & & & 0.1383563 \\
sigma_e & & & $(0.1556563)$ \\
rho & 0.6769464 & 0.65156218 & 0.68346768 \\
\hline Erop & 0.41989428 & 0.45186623 & 0.42284094 \\
& 0.72215537 & 0.67523815 & 0.72319519 \\
\hline
\end{tabular}

Erro padrão em (). 1. Instrumentos: lpm_conc_1km lprecocompragas; 2. lpm_conc_1km lprecocompragas ltanksg; 3. lpm_conc_1km lprecocompragas ltanksg. Elaboração própria.

Com base na estimação estrutural, o sobrepreço foi de $\mathrm{R} \$ 0,38$ centavos (16\%), ao contrário da redução de preço observada na equação reduzida. Isso impacta a estimação de dano e a calibração das multas, abordadas na próxima sessão. 
Figura 2. PReÇo de Venda de ETANol e Preços Estimados

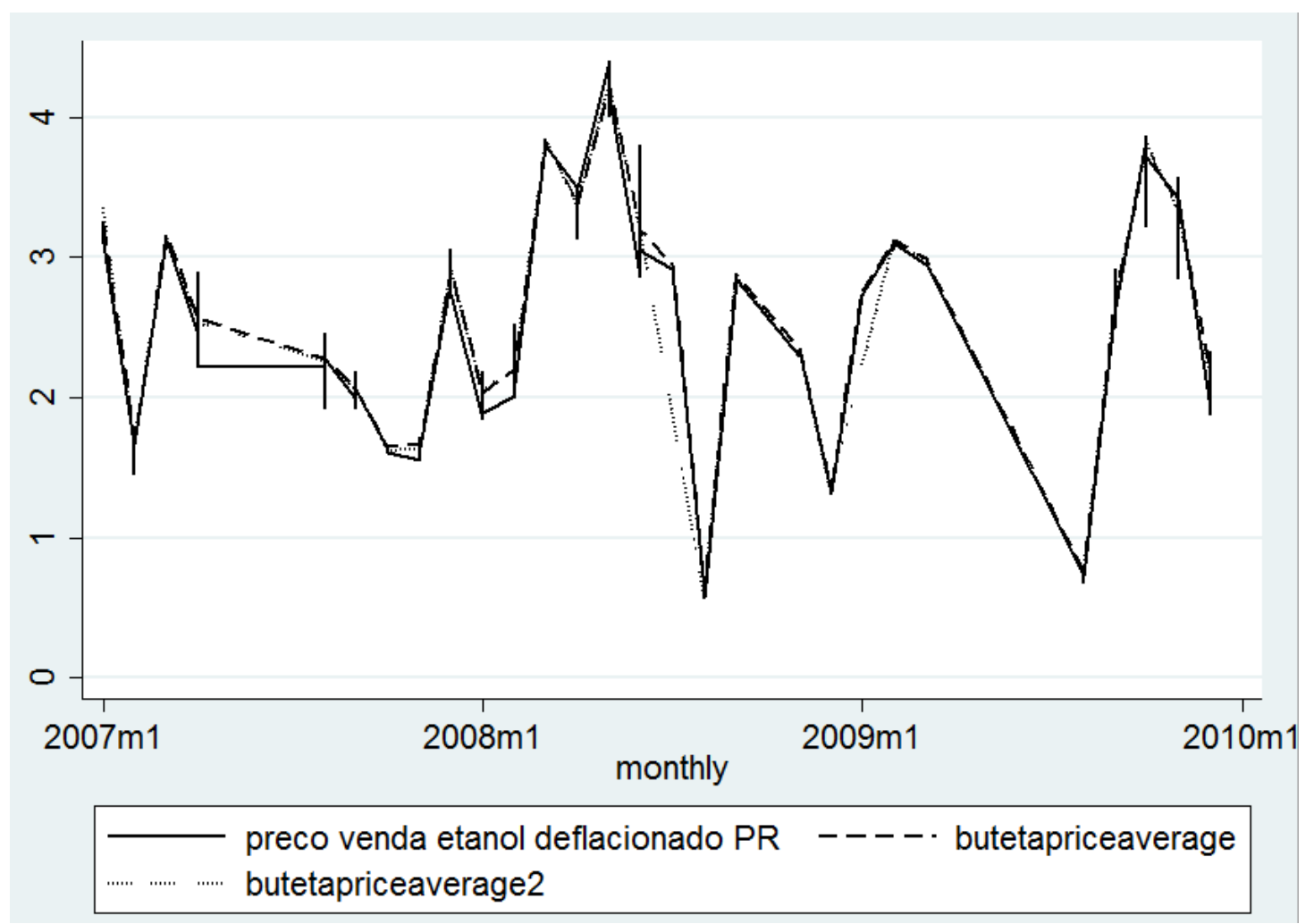

Elaboração própria.

\section{Avaliando a Política de Concorrência: Multas x Danos Estimados}

Para calcular os danos estimados, com base nos resultados das abordagens reduzidas e estrutural, foi necessário considerar os efeitos cruzados entre o preço de venda tanto da gasolina quanto do etanol. Para exemplificar, na equação reduzida, o aumento de $\mathrm{R} \$ 1,00$ no preço do etanol esteve relacionado a um aumento de $\mathrm{R} \$ 0,093$ no preço da gasolina. Considerando o fato que os participantes do cartel reduziram o preço do etanol em $\mathrm{R} \$ 0,038$, mantendo a mesma proporção, isso é equivalente a assumir que o aumento líquido no preço da gasolina foi de R\$0,135. Para etanol, o aumento foi de R\$0,02 (Tabela $9)^{14}$.

TABELA 9. ESTIMAÇÕES DE SOBREPREÇO NO MODELO REDUZIDO (R\$)

\begin{tabular}{|c|c|c|c|c|c|c|}
\hline & $\begin{array}{l}\text { Sobrepreço do Cartel } \\
\text { (“dummyidcartel”) }\end{array}$ & Coeficientes cruzados & Efeito preço & Efeito líquido & $\begin{array}{l}\text { "But for price" } \\
\text { (média) }\end{array}$ & $\begin{array}{l}\text { Sobrepreço } \\
\text { líquido }\end{array}$ \\
\hline Gasolina & 0,139 & 0,093 & $-0,003$ & 0,135 & 3,798 & $3,70 \%$ \\
\hline Etanol & $-0,038$ & 0,424 & 0,059 & 0,020 & 2,430 & $0,86 \%$ \\
\hline
\end{tabular}

Elaboração própria.

\footnotetext{
14 Efeito líquido gasolina: dummyidcartel_gas + dummyidcartel_etanol*RECOVENDAETANOLd; Efeito líquido etanol: dummyidcartel_etanol + dummyidcartel_gas* PRECOVENDAGASd
} 
No modelo estrutural, foi considerado que os postos, em um jogo à la Cournot, seguem uma regra de mark-up descrita na equação 11. O dano obtido foi maior, principalmente no mercado de etanol, devido ao efeito cruzado (Tabela 10). O fato do modelo estrutural considerar o peso-morto é uma hipótese para a diferença entre os modelos.

TABELA 10. ESTIMAÇÕES DE SOBREPREÇO NO MODELO ESTRUTURAL (R\$)

\begin{tabular}{lllllc}
\hline \hline & & & "But for price” & "But for price” & Sobrepreço \\
Sobrepreço s/ efeito cruzado & Sobrepreço c/ efeito cruzado & s/ efeito cruzado & (média) & líquido \\
Gasolina & 0,389 & $9,849 \%$ & 3,537 & 3,658 & $6,68 \%$ \\
Etanol & 0,382 & $16,325 \%$ & 1,957 & 2,028 & $12,5 \%$ \\
\hline
\end{tabular}

Vale à pena mencionar que o sobrepreço obtido está dentro das estimativas encontradas na literatura, como em Connor e Bolotova (2006). Alguns estudos afirmam que há uma relação direta entre o sobrepreço, ambientes oligopolísticos e altas barreiras à entrada15. Como a situação do varejo de combustíveis não se enquadra nesses ambientes, era de se esperar que o sobrepreço estimado fosse menor que em outras indústrias. Esse resultado reflete a preocupação dos participantes do cartel em determinar o preço "justo" para cada um dos postos, como observado nos autos do processo sobre a combinação de preços até a terceira casa decimal16.

Além dos efeitos cruzados, são necessários dados obre a quantidade vendida por cada um dos postos por mês; contudo, essa informação não está disponível para cada participante do cartel, podendo causar uma subestimação dos efeitos. Considerando o fato que os varejistas envolvidos no cartel também eram líderes de preços na região, estimouse então o dano considerando o volume total vendido em ambos mercados de gasolina e etanol durante o período do cartel. Os danos estimados com base nos modelos reduzido e estrutural estão reportados na Tabela 11, sendo que os resultados do modelo estrutural indicam um maior ganho auferido $(\mathrm{R} \$ 574.937,20$ contra $\mathrm{R} \$ 123.871,57$ no modelo reduzido). Os valores aparentemente baixos são atribuídos ao curto período do cartel (3 meses).

\footnotetext{
15 Bolotova et al (2008) descrevem uma correlação interessante entre o sobrepreço e as características das indústrias.

16 Em um dos diálogos entre Djalma Guarda Junior e Djalma Guarda, filho e pai, o primeiro insiste em corrigir que o preço combinado de etanol era de $\mathrm{R} \$ 1,269$, não $\mathrm{R} \$ 1,259$, como o pai acreditava.
} 
TABELA 11. ESTIMAÇÃO DE DANO (R\$)

\begin{tabular}{lllll}
\hline \hline & Modelo reduzido (R) & Modelo estrutural(E) & C/ efeito cruzado(R) & C/ efeito cruzado(E) \\
Gasolina & $134.515,8$ & 457.936 & $131.048,3$ & $295.352,8$ \\
& & & & \\
Etanol & $-10.644,23$ & $117.001,2$ & -15.167 .73 & $92.648,25$ \\
Total & $\mathbf{1 2 3 . 8 7 1 , 5 7}$ & $\mathbf{5 7 4 . 9 3 7 , 2 0}$ & $\mathbf{1 1 5 . 8 8 0 , 5 7}$ & $\mathbf{3 8 8 . 0 0 1 , 0 5}$ \\
\hline
\end{tabular}

Elaboração própria.

O total das multas aplicadas pelo CADE somaram R\$10.964.962,2, 20 vezes maior que os danos totais estimados. A teoria de poder disuasório ótimo ("deterrence effects”) afirma que as multas devem ser inversamente proporcionais à probabilidade de detecção do crime. Se os participantes do cartel consideram apenas que este é uma decisão econômica para obter maiores lucros, sem considerar princípios éticos, a questão a ser respondida é se os ganhos com o cartel compensam as penalidades esperadas (se existirem). As probabilidades de detecção de crimes são extremamente árduas de se mensurar, apesar de haver alguns estudos sobre o assunto. Por exemplo, a pesquisa de Allain et al (2013) faz uma revisão da literatura sobre essas probabilidades, que variam de $10 \%$ a $33 \%$, sendo consistentes com as probabilidades de detecção de outros crimes.

Com base nessas informações, observa-se que as multas estabelecidas pelo CADE foram de ordem superior ao suposto efeito dissuasório. Contudo, o alto valor da multa aplicada relaciona-se a uma probabilidade de detecção de ordem de 5\%, o que é realístico para a Autoridade de Concorrência nacional, visto sua limitada capacidade, tanto orçamentárias quanto de pessoal, diante das dimensões geográficas do país.

TABela 12. Multas (Pena) Considerando a Probabilidade De DetecÇão ${ }^{17}$

\begin{tabular}{cccccc}
\hline \hline Probabilidade de ser pego & Pena 1 & Pena 2 & Pena 3 & Pena 4 \\
$\mathbf{0 . 0 5}$ & $\mathbf{2 ~ 4 7 7 ~ 4 3 1 . 4 0}$ & $\mathbf{1 1 4 9 8 7 4 4 . 0 0}$ & $\mathbf{2 ~ 3 1 7 ~ 6 1 1 . 4 0}$ & $\mathbf{7 7 6 0 ~ 0 2 1 . 0 0}$ \\
0.1 & 1238715.70 & 5749372.00 & 1158805.70 & 3880010.50 \\
0.15 & 825810.47 & 3832914.67 & 772537.13 & 2586673.67 \\
0.3 & 412905.23 & 1916457.33 & 386268.57 & 1293336.83 \\
\hline
\end{tabular}

Elaboração própria.

\section{Considerações Finais}

A necessidade de se promover avaliações de políticas públicas é importante para justificar os gastos públicos. A análise de punição aos cartéis é uma das formas de se

\footnotetext{
17 Pena 1: multa com base no modelo reduzido s/efeito cruzado; Pena 2: multa com base no modelo estrutural s/ efeito cruzado; Pena 3: multa com base no modelo reduzido, c/ efeito cruzado; Pena 4: multa com base no modelo estrutural, c/ efeito cruzado.
} 
verificar como o CADE tem lidado com a matéria, considerando sua dificuldade de detecção e os custos envolvidos nas investigações, como recursos humanos. A análise acima é uma das primeiras iniciativas a promover uma avaliação sobre o tamanho das multas aplicadas pelo Conselho nos casos mencionados e sua relação com o efeito dissuasório.

A lei 12.529/11 estabelece que as multas em caso de cartel podem variar entre 0,1\% e $20 \%$ do faturamento bruto da companhia no ano que antecede a instauração do processo investigativo. A lei também afirma que as multas não devem ser inferiores ao ganho auferido pelas empresas durante a conduta ilegal, quando possível calculá-lo. Essa estimativa, contudo, não parte de um cálculo trivial, de modo que a iniciativa de avaliar casos passados para comparar o dano com as multas aplicadas contribui para o aprimoramento das decisões do CADE. No Brasil, esse é o terceiro estudo, até onde se sabe, que busca avaliar a relação entre os danos do cartel e a aplicação das multas ${ }^{18}$; contudo, este é o primeiro a considerar os efeitos dissuasórios indicando que, ao contrário das demais análises, a decisão do Conselho acabou por, indiretamente, considerar esse efeito, possivelmente por ter impacto direto ao consumidor final.

Este trabalho está relacionado a duas vertentes da literatura econômica: uma referente à estimativa da demanda de etanol e sua substituibilidade pela gasolina; e outra ao cálculo dos danos causados pelos cartéis. Anderson (2012), um dos primeiros a fornecer estimativas para a elasticidade do etanol, afirma que este combustível é muito sensível aos preços relativos. Este artigo contribui para esta descoberta, uma vez que a estratégia de preços dos cartelistas não apenas um aumento no preço da gasolina, mas também uma queda no preço do etanol para manter os preços relativos dentro de uma margem equivalente a sua eficiência energética e às distâncias de cada posto em relação ao centro da cidade. Este trabalho também inova com a utilização de uma base de dados desagregadas para o mercado brasileiro de etanol, considerado o mais consolidado em termos de veículos flex-fuel no mundo.

Os resultados obtidos no estudo podem colaborar para a dosimetria dos cálculos das multas, que devem considerar não apenas a gravidade da conduta, mas as características de cada indústria. Aquela com menor número de participantes deve ser objeto de multas maiores que setores cuja conduta ocorre em ambientes oligopolizados, mas com maior número de concorrentes.

\footnotetext{
18 Além do estudo do CADE (2016). Afonso de Féres (2017) revisam a recente multa aplicada pelo CADE no caso do cartel de GLP em Pernambuco.
} 
Por fim, como agenda para próximas pesquisas, ressalta-se a importância de se avaliar especificações diferentes para a análise da demanda, especialmente considerando que postos de combustíveis vizinhos têm maior influência sobre os preços que postos distantes ou fora do raio de preferência dos consumidores. A caracterização da demanda para ambos os combustíveis pode ser mais precisa se considerarmos que a escolha de postos de combustíveis, sob a ótica do consumidor, parte da hipótese de que eles são bens diferenciados, devido às características de marca, por exemplo, ou de distância entre a rota escolhida e a localização dos postos.

\section{Referências}

AFONSO, Nathalie Gressler; FÉRES, José. Cartel damage evaluation: a case study of the liquefied petroleum gas sector in Pará, Brazil. Anais do 45 Encontro da Anpec, Natal, p.0-20, dez. 2017. Anual. Disponível em: <https://www.anpec.org.br/encontro/2017/submissao/files_I/i80295bd1f49b93d5f1c87cf78a505f303.pdf>. Acesso em: 23 abr. 2018.

ALLAIN, Marie-laure et al. Are cartel fines optimal? Theory and evidence from the European Union. International Review Of Law And Economics, [s.l.], v. 42, p.38-47, jun. 2015. Elsevier BV. http://dx.doi.org/10.1016/j.irle.2014.12.004.

ANDERSON, Soren T.. The demand for ethanol as a gasoline substitute. Journal Of Environmental Economics And Management, [s.l.], v. 63, n. 2, p.151-168, mar. 2012. Elsevier BV. http://dx.doi.org/10.1016/j.jeem.2011.08.002.

ANFAVEA. Veículos - produção, vendas domésticas e exportações. 2008. Disponível em http://www.anfavea.com.br/anuario2008/capitulo2a.pdf.

BONNET, Céline, DUBOIS, Pierre. Non Linear Contracting and Endogenous Buyer Power between Manufacturers and Retailers: Identification and Estimation on Differentiated Products. mimeo, 2007.

BOLOTOVA, Y.; CONNOR, J. M.; MILLER, D. J.. FACTORS INFLUENCING THE MAGNITUDE OF CARTEL OVERCHARGES: AN EMPIRICAL ANALYSIS OF THE U.S. MARKET. Journal Of Competition Law And Economics, [s.l.], v. 5, n. 2, p.361381, 28 ago. 2008. Oxford University Press (OUP). http://dx.doi.org/10.1093/joclec/nhn025.

CADE. Processo 08012.011668-2007-30. 2010.

CADE. Varejo de Gasolina. Cadernos do CADE. 2014 
CLARK, Emily, HUGHES, Mat, WIRTH, David. Analysis of Economic Models for the calculation of damages. Study on the conditions of claims for dames in case of infringement of EC Competition Rules. 2004.

CLARK, Robert; HOUDE, Jean-françois. Collusion with Asymmetric Retailers: Evidence from a Gasoline Price-Fixing Case. American Economic Journal: Microeconomics, [s.l.], v. 5, n. 3, p.97-123, ago. 2013. American Economic Association. http://dx.doi.org/10.1257/mic.5.3.97.

CLARK, Robert; HOUDE, Jean-françois. The Effect of Explicit Communication on pricing: Evidence from the Collapse of a Gasoline Cartel. The Journal Of Industrial Economics, [s.l.], v. 62, n. 2, p.191-228, jun. 2014. Wiley-Blackwell. http://dx.doi.org/10.1111/joie.12042.

CONNOR, John M.; BOLOTOVA, Yuliya. Cartel overcharges: Survey and metaanalysis. International Journal Of Industrial Organization, [s.l.], v. 24, n. 6, p.11091137, nov. 2006. Elsevier BV. http://dx.doi.org/10.1016/j.ijindorg.2006.04.003.

CONNOR, John M. Cartels and Antitrust Portrayed: Market Effects and Damages. SSR1 Working Paper. 2009.

COVRIG, Claudiu. How sugar and ethanol impact each other? Seul: Platts, 2014. 22 slides, color. Disponível em: <https://www.platts.kr/IM.Platts.Content/ProductsServices/ConferenceandEvents/2014/ sc451/presentations/Claudiu-Covrig.pdf>. Acesso em: 23 abr. 2018.

DAVIS, Peter; GARCÉS, Eliana. Quantitative Techniques for Competition and Antitrust Analysis. Nova York: Princeton University Press, 2009.

HOUDE, Jean-françois. Spatial Differentiation and Vertical Mergers in Retail Markets for Gasoline. American Economic Review, [s.l.], v. 102, n. 5, p.2147-2182, ago. 2012. American Economic Association. http://dx.doi.org/10.1257/aer.102.5.2147.

HUSCHELRATH, Kai, WEIGAND, Jurgen. Framework to Enforce Anti-Predation Rules, A. World Competition, v. 33, n. 209. 2010.

LAITENBERGER, Ulrich; SMUDA, Florian. ESTIMATING CONSUMER DAMAGES IN CARTEL CASES. Journal Of Competition Law And Economics, [s.l.], p.955-973, 22 out. 2015. Oxford University Press (OUP). http://dx.doi.org/10.1093/joclec/nhv030. LUCINDA, Claudio; SEIXAS, Renato. Prevenção Ótima de Cartéis: O Caso dos Peróxidos no Brasil. Documento de Trabalho DEE/CADE. Brasília, 2016.

MILLER, Nathan H.; OSBORNE, Matthew. Spatial differentiation and price discrimination in the cement industry: evidence from a structural model. The Rand 
Journal Of Economics, [s.l.], v. 45, n. 2, p.221-247, 7 maio 2014. Wiley-Blackwell. http://dx.doi.org/10.1111/1756-2171.12049.

MINISTÉRIO DO MEIO AMBIENTE. I Inventário Nacional de Emissões Atmosféricas por Veículos Automotores Rodoviários. 2013. Disponível em $<$ http://www.mma.gov.br/estruturas/163/_publicacao/163_publicacao27072011055200. pdf>. Acesso em: 23 abr. 2018.

OCDE. Assessment of the Impact of Competition Authorities' Activities. Paris: Ocde, 2013. (DAF/COMP/WP2). Disponível em: $<$ http://www.oecd.org/daf/competition/Guide-competition-impact-assessmentEN.pdf>. Acesso em: 23 abr. 2018.

OCDE. Competition in Road Fuel. Paris: Ocde, 2013. Disponível em: <https://www.oecd.org/competition/CompetitionInRoadFuel.pdf>. Acesso em: 23 abr. 2018.

OCDE. Guide for Helping Competition Authorities Assess the Expected Impact of their Activities. Paris: Ocde, 2014. Disponível em: $<$ https://www.oecd.org/daf/competition/Guide-competition-impact-assessmentEN.pdf>. Acesso em: 23 abr. 2018.

OCDE. Reference guide on ex-post evaluation of competition agencies' enforcement decisions. Paris: Ocde, $2016 . \quad$ Disponível em: <http://www.oecd.org/daf/competition/Ref-guide-expost-evaluation-2016web.pdf>. Acesso em: 23 abr. 2018.

OXERA. Quantifying Antitrust Damages. Towards Non-Binding Guidance for Courts. Luxemburgo: $2009 . \quad$ Oxera, Disponível em: $<$ https://www.oxera.com/Oxera/media/Oxera/Quantifying-antitrustdamages.pdf?ext=.pdf $>$. Acesso em: 23 abr. 2018.

PETRIN, Amil; TRAIN, Kenneth. A Control Function Approach to Endogeneity in Consumer Choice Models. Journal Of Marketing Research, [s.l.], v. 47, n. 1, p.3-13, fev. 2010. American Marketing Association (AMA). http://dx.doi.org/10.1509/jmkr.47.1.3.

RAGAZZO, Carlos Emmanuel Joppert; SILVA, Rutelly Marques da. Aspectos Econômicos e Jurídicos sobre Cartéis na Revenda de Combustíveis: Uma Agenda para Investigações. Brasilia: Seae/mf, 2006. Disponível em: $<$ http://seae.fazenda.gov.br/central-de-documentos/documentos-detrabalho/documentos-de-trabalho-2006/DT_40.pdf>. Acesso em: 23 abr. 2018. 
SALVO, Alberto; HUSE, Cristian. Is Arbitrage Tying the Price of Ethanol to that of Gasoline? Evidence from the Uptake of Flexible-Fuel Technology. The Energy Journal, Estocolmo, v. 32, n. 3, p.119-148, jan. 2011.

SALVO, Alberto; HUSE, Cristian. Build it, but will they come? Evidence from consumer choice between gasoline and sugarcane ethanol. Journal Of Environmental Economics And Management, [s.l.], v. 66, n. 2, p.251-279, set. 2013. Elsevier BV. http://dx.doi.org/10.1016/j.jeem.2013.04.001.

SECRETARIA DE DIREITO ECONÔMICO. Nota Técnica para Averiguação Preliminar, Processo n. ${ }^{\circ}$ 08012.000642/2010-61. 2010.

VERBOVEN, Frank; VAN DIJK, Theon. CARTEL DAMAGES CLAIMS AND THE PASSING-ON DEFENSE. The Journal Of Industrial Economics, [s.l.], v. 57, n. 3, p.457-491, set. 2009. Wiley-Blackwell. http://dx.doi.org/10.1111/j.14676451.2009.00390.x.

VILLAS-BOAS, S. B.. USING RETAIL DATA FOR UPSTREAM MERGER ANALYSIS. Journal Of Competition Law And Economics, [s.l.], v. 3, n. 4, p.689-715, 28 jun. 2007. Oxford University Press (OUP). http://dx.doi.org/10.1093/joclec/nhm030. WEBER, Sylvain; PÉCLAT, Martin. A Simple Command to Calculate Travel Distance and Travel Time. Neuchatel: Irene Working Papers, 2017. Disponível em: <ftp://ftp.repec.org/opt/ReDIF/RePEc/irn/pdfs/WP16-10.pdf>. Acesso em: 23 abr. 2018. 